\title{
TESTIGOS PRIVILEGIADOS EN EL ÁMBITO URBANO: LAS MONJAS DEL CONVENTO DE SANTA MARÍA EN CÁDIZ O LA CREACIÓN FEMENINA EN CLAUSURA COMO POSIBLE FUENTE HISTÓRICA
}

\author{
FRÉDÉRIQUE MORAND
}

Universidad París VIII

RESUMEN: A partir del supuesto «encierro» de las monjas gaditanas en sus respectivos conventos, intentaré demostrar, con algunos acontecimientos vividos por la comunidad de Concepcionistas calzadas de Santa María que este monasterio fue una ventana abierta para la historia de la ciudad, así como en la vida social de los gaditanos: la catástrofe de El Puerto de Santa María en 1779 o la venida de los Reyes en 1796 son dos claros ejemplos de ello. A través de la pluma de una de sus religiosas, Sor María Gertrudis de la Cruz Hore (1742-1801), descubrimos el punto de unión entre la sociedad seglar y reglar a finales del Antiguo Régimen en Cádiz.

Palabras Clave: Monjas. Escritura. Historiogrfía. Cádiz. Siglo XVIII.

ABSTRACT: During the second half of the $18^{\text {th }}$ century, nuns in Cadiz were supposedly locked away in their respective monasteries. In this essay, I will try to prove that these monasteries were actually in close contact with the city. Based on writings by the nun Sor María Gertrudis de la Cruz Hore (1742-1801) from the Concepcionist convent of Santa Maria, various manuscript sources (including poems and letters) bear witness to the many links between the nuns and the population of Cádiz, for instance in the catastrophe of 1779 in El Puerto de Santa Maria or the King's visit of 1796. Furthermore, these sources help us better to understand life in this female community.

KEY WORDS: Nuns, Writing, Historiography, Cádiz. $18^{\text {th }}$ century.

Este artículo pretende sacar provecho de fuentes intraconventuales para dar a conocer la vida extraconventual a finales del siglo XVIII en la bahía de Cádiz 
y valerse de fuentes seglares para historiar el curso de la vida claustral en el monasterio de la Concepción, situado en el más alto y popular Barrio de Santa María en Cádiz. Esta analogía entre el universo de la clausura femenina y las vivencias de los gaditanos me la proporcionó Sór María Gertrudis Hore y Ley (1742-1801) y su afición a la literatura: primero, compuso un poema manuscrito sobre algún desgraciado evento ocurrido en el Puerto de Santa María en el año 1779 y luego, en 1796, publicó una carta en la prensa madrileña en relación con la venida de los Reyes ${ }^{1}$. Esta erudita monja, casada, vivió los últimos veintitrés años de su existencia en esta comunidad de religiosas Concepcionistas Calzadas, y empuñó el cálamo en diversas ocasiones para dejar constancia de su existencia en esta ciudad abierta al mar.

Interesémonos, en primer lugar, por los estudios ya realizados en materia conventual y, entre ellos, en los de Arturo Morgado García. El profesor se preguntó cómo transcurría la vida claustral en las tres comunidades gaditanas en el siglo XVIII (Santa María, la Piedad, Candelaria). Para ello utilizó, como de costumbre para adentrarse en el universo conventual femenino, los mandatos de visitas para comentar el quehacer de las monjas ${ }^{2}$. Las peticiones y demandas de los visitadores giraban casi todas en torno al respeto de la regla y constituciones, uno de los aspectos menos respetado por las monjas (falta de silencio, amistades particulares, conversaciones delante de la puerta reglar, etc.), en

1 B.N.M.: Hore, María Gertrudis, Poesías Varias (principalmente) del siglo XVIII, Tomo IV, Ms 4061 «Ex-Libris D. A-Mosty», fols. 272-273. V. Apéndice 1. El romance endecasílabo: «Habiendo sabido un Sujeto el desgraciado acaecimiento del Puerto de Santa María prorrumpió en el Siguiente.» B.N.M.: Hore, María Gertrudis (H.D.S), «Carta de una Religiosa de Cádiz de 11 de Marzo de 1796», Diario de Madrid, núm. 89, martes 29 de marzo de 1796, pp. 365-367. Original conservado en el Tomo IV, Ms 4061, fols. 268-269 y publicado en MORAND, Frédérique: Doña María Gertrudis Hore (1742-1801), vivencia de una poetisa gaditana entre el siglo y la clausura, Premio de Investigación «María Isidra de Guzmán 2003», Alcalá de Henares, 2004, pp. 256-258.

2 En la actualidad existen el monasterio de Santa María del Arrabal y el de la Piedad, dos comunidades Concepcionistas en su vertiente Calzada y Descalza. El monasterio de Candelaria, institución de religiosas Agustinas Calzadas ha desaparecido. A.D.C.: leg. 15 bis, «Papeles del escrutinio hecho en la elección de abadesa descalza de esta ciudad de Cádiz el año de 1739.» Citado por Morgado García, Arturo: Iglesia y sociedad en el Cádiz del siglo XVIII, Cádiz, 1989, pp. 172173. A. Morgado y el Padre Antón fueron pioneros en el estudio de las comunidades femeninas gaditanas en el Setecientos. Morgado García, Arturo: «Los ingresos de novicias en el Convento de Nra. Sra. de la Candelaria (Cádiz) 1600-1900» en Gades (Jerez) 15 (1987) pp. 79-94. Del mismo autor: «Los conventos de monjas concepcionistas en el Cádiz del siglo XVIII» en La Orden Concepcionista, Actas del I Congreso Internacional (León) vol. 1 (1990) pp. 299-311. «Modelos de comportamiento religioso en la España del siglo XVIII. El caso del convento de concepcionistas franciscanas descalzas de nuestra señora de la Piedad (Cádiz)» en Archivo ibero-americano (Madrid) 201-202, (1991) pp. 201-215. ANTÓN SOLÉ, Pablo: «La observancia de las monjas gaditanas en el siglo XVIII» en VII Encuentro de la Ilustración al Romanticismo. Cádiz, América y Europa ante la modernidad. La mujer en los siglos XVIII y XIX (Cádiz) (1993) pp. 139-147. Del mismo autor: La Iglesia gaditana en el siglo XVIII, Cádiz, 1994, pp. 348-350. 
palabras del profesor. Para concluir apuntó, con razón, que a principios del siglo XIX la situación de los monasterios gaditanos seguía igual:

(...) se evite cuanto sea posible la entrada de hombres (...) que no entren parientes a visitar religiosas enfermas. Que ha habido demasiada condescendencia en franquear la portería aun en tiempos que ni se permiten los locutorios $(. . .)^{3}$

Interesa resaltar que, como lo apuntó Arturo Morgado, a veces fueron las propias monjas las que protestaron con «acritud» ante la frivolidad de los seglares: en una carta escrita en 1761, la abadesa de Santa María se lamentaba de la apertura de una casa de truco justo en frente de su convento, asegurando que acabaría provocando una verdadera «plaga de mujercillas indignas en todo el barrio» ${ }^{4}$.

Pero, excluyendo aquellas breves pinceladas, estos aspectos nos están casi desconocidos. Quizás el silencio de la documentación indica que las religiosas de la ciudad, muy encerradas en sus respectivos conventos, apenas tuvieron algunas relaciones con el ambiente urbano y constituyeron un mundo totalmente aparte... y olvidados.

La reflexión es tentadora. Sin embargo, algunas fuentes documentales nos permiten profundizar en el conocimiento de esta sociedad reglar, en este desconocido universo de mujeres.

\section{FUENTES EXTRACONVENTUALES PARA ACERCARSE A LA CLAUSURA}

\section{María \\ 1.1. La construcción del puente San Alejandro en El Puerto de Santa}

Tanto los gaditanos como los pueblos circunvecinos necesitaban de vías de transporte para las mercancías. Los vecinos del Puerto de Santa María vivían principalmente del comercio, disponían de una vía única por mar de acceso difícil; los barcos se enfrentaban continuamente a un camino marítimo en muy mal estado. El desarrollo y la mejora de las vías de comunicación permitirían un crecimiento de las actividades económicas, y facilitarían sin duda los inter-

3 Son las palabras del obispo Javier de Utrera. A.D.C: Secretaria, leg. 47, «Puntos que tocaron en el escrutinio secreto de las religiosas del convento de Santa María antes de la elección de la abadesa.». Citado por MORGADO GarCíA, A.: Iglesia y sociedad en el Cádiz del siglo XVIII, p. 175.

4 A.D.C., Secretaría, leg. 16, «Estos papeles se produjeron sobre los perjuicios que ocasionaba una casa de truco inmediata al convento de Santa María.» Citado por A. Morgado García, Op. cit., p. 180.

5 Ibídem. 
cambios con América ${ }^{6}$. José Blanco-White dejó un testimonio vivo y de interés sobre la comunicación por mar entre Cádiz y El Puerto:

El viaje por mar a este último dura una hora y media y la comunicación es tan frecuente como la de una gran ciudad con sus barrios suburbanos. El movimiento de barcos de pasajeros por la bahía es continuo desde el amanecer hasta la puesta del sol. El viaje, sin embargo, no deja de ser peligroso tanto cuando sopla el levante con fuerza durante el verano como con los temporales del invierno. Además, en la barra del Guadalete, que es el río que desemboca en la bahía por el Puerto, hay grandes bancos de arena que cambian de lugar y que causan no pocas víctimas todos los años ${ }^{7}$.

Es fácil entender que la existencia de dos caminos, uno por mar, otro por vía terrestre, permitiría una mejora de los intercambios comerciales así como una mayor seguridad para la población. La construcción de un puente facilitaría el flujo de mercancías entre Cádiz y El Puerto, a la vez que permitiría mejorar la situación comercial en decadencia ya en los años $1770^{8}$. Por tanto, las autoridades decidieron la construcción de un puente. Para llevar a cabo el proyecto se requirió la ayuda del conde de O' Reilly9 ${ }^{9}$ quien decidió, también por razones financieras, que se construiría no en las ruinas del puente romano sino donde había sido edificado un muelle de madera llamado el «Muelle de Estacas». Se decidió la construcción de un puente de madera (y no de piedra) cuya parte central, las compuertas, permitirían el paso de los barcos que llegaban de Jerez de la Frontera ${ }^{10}$. Por su mayor capacidad sería más fácil cargar tanto las mercancías como las personas.

Este proyecto ya había sido discutido y decidido por las dos municipalidades el 15 de febrero de 1777, es decir, poco antes de que Sor María Gertrudis

6 Fernández De Pindeo, Emiliano: Centralismo, Ilustración y Agonía del Antiguo Régimen (1715-1833), Barcelona, 1981: Historia de España, tom. VII, p. 143. Citado por SÁNCHEZ GONZÁLEZ, Rafael: «El puente de barcas sobre el río Guadalete en El Puerto de Santa María (1779)» en Gades 13 (1985) p. 159.

7 Blanco White, José: Cartas de España, Madrid, 1986, 4. ${ }^{\text {a }}$ ed., p. 47.

8 Existía un camino por tierra dando la vuelta a la bahía pero era muy largo. SÁnCHEZ GONZÁLEZ, Rafael: Op. cit., p. 160.

9 El conde de O'Reilly (1723-1794) llegó a Cádiz como Gobernador Militar y Político en 1780, y al Puerto de Santa María en 1776 como Capitán General del Mar Océano tras la derrota de Argel (1775). Tuvo mucha influencia en Andalucía así como en la vida local. Irlandés al servicio de España fue uno de los mayores reformadores del ejército español del XVIII, gobernador de Madrid, Andalucía (1775) y Cataluña (1794) (no llegó a tomar posesión del cargo, murió camino del destino). ReCiO MORALES, Óscar: «Una nación inclinada al ruido de las armas. La presencia irlandesa en los Ejércitos españoles, 1580-1818: ¿ La historia de un éxito?»en Tiempos Modernos (Revista electrónica) 10, (2004), pp. 1-15. ANTÓN SOLÉ, Pablo: «El Cádiz del conde de O’Reilly»en Cádiz en la Carrera de las Indias (Cádiz) (1967), pp. 6-8.

${ }_{10}$ El puente abriría un camino más corto y más directo que el acceso marítimo; además sería menos costoso para las poblaciones cercanas (Isla de León, Campo de Gibraltar): una oportunidad para los habitantes de la ciudad. Los planos de la obra fueron realizados por José Molina y el coste total fue de 26752 r.s de v.n. SÁNCHeZ GonZÁleZ, Rafael: Op. cit., pp. 161-166. SANCHO DE Sopranis, Hipólito: Historia del Puerto de Santa María, Cádiz, 1943, pp. 466-473. 
de la Cruz Hore, «una de la más relevantes poetisas del siglo XVIII» ${ }^{11}$, entrase en el monasterio de Santa María del Arrabal en Cádiz. Unica religiosa casada de esta comunidad de Concepcionistas Calzadas, novicia de treinta y seis años a principios de 1779, la Madre Cruz profesó al año siguiente, con la licencia de su esposo ${ }^{12}$.

\section{FUENTES CONVENTUALES PARA ACERCARSE A LA VIDA SEGLAR}

\subsection{El desastre: entre rima y rigor científico}

Pero, ¿ por qué interesarse en este evento si la Hija del Sol, como la denominaron sus coetáneos por su belleza y su erudición, estaba recluida ya desde hacía unos diez meses en la cerrada clausura?

Porque en uno de los manuscritos de la Biblioteca Nacional de Madrid estaba conservado, entre algunas de las creaciones de la poetisa, un romance endecasílabo fechado a 17 de febrero de 1779 , pero sin que tuviese constancia ni del estatuto, ni del sexo de su autora: «Habiendo sabido un Sujeto el desgraciado acaecimiento del Puerto de Santa María prorrumpió en el Siguiente» ${ }^{13}$.

Ingresada en la clausura desde mediados de 1778, Sor Gertrudis, religiosa de coro, dama de la alta sociedad gaditana, relató en verso la catástrofe del puente San Alejandro: el mismo día de la inauguración se derrumbó. Es de notar que había oído hablar de la catástrofe. El daño provocado no pudo más que penetrar la clausura, ser conocido por todas las comunidades de los alrede-

11 Bolufer Peruga, Mónica: «Escritura femenina y publicación en el siglo XVIII: de la expresión personal a la «República de las letras»»en Género y ciudadanía. Revisiones desde el ámbito privado (Madrid) (1999) p. 203.

12 Esteban Fleming juró castidad y se marchó a Nueva España poco después. La tardía vocación de su esposa, acompañada de fugaces huellas manuscritas con claro carácter de castigo, aunque sin prueba científica, pero contando con el apoyo del derecho canónico, me invitó a conjeturar sobre las verdaderas razones de su enclaustramiento. A mi parecer, Gertrudis Hore fue una de estas monjas «forzadas» a vestir el velo. Profesó por razones de adulterio invocando, por supuesto, y con la complicidad de la Iglesia, otra causa. A mi juicio, Fleming, deseoso de recobrar su libertad, sacó provecho de lo que le ofrecía el derecho, librándose, a la vez que preservaba el honor, de esta esposa entonces inútil y demasiada frívola. Esta erudita dama murió en su celda el 9 de agosto de 1801 siendo secretaria y tras haber sido reconocida como una de las escasas autoras dignas de representar la lírica del setecientos al lado de sus correligionarios masculinos. V. MORAND, Frédérique: «Primer acercamiento a la poetisa y religiosa Doña María Gertrudis Hore (1742-1801): alias la «Hija del Sol»en Cuadernos de Ilustración y Romanticismo. Revista del Grupo de Estudios del Siglo XVIII de la Universidad de Cádiz (Cádiz) 10 (2002) pp. 171-184. De la misma autora: «i Qué sabemos del hijo de la monja Sor María Gertrudis de la Cruz Hore (1742-1801) y de su esposo, Esteban Fleming?» en Dieciocho, Vol. 28, (Spring, 2005) University of Virginia, Charlottesville, VA., pp. 141-158.

13 B.N.M.: Hore, María Gertrudis, Ms 4061, fols. 272-273. V. Apéndice 1. El romance endecasílabo. 
dores. ¿Cómo ignorar el gran número de víctimas? Un accidente que fue la causa del fuerte aumento del índice de mortalidad durante ese año de $1779^{14}$. Empecé a buscar otros ecos literarios sobre la catástrofe; consulté la obra de Manuel Martínez Alfonso, un ensayo de "geografía literaria» sobre El Puerto de Santa María pero no se tenía constancia del poema, y tampoco de otro ${ }^{15}$. Por tanto, los versos manuscritos de esta monja de clausura ofrecían más datos sobre un evento que interesaba directamente a los habitantes del Puerto de Santa María ${ }^{16}$.

La historiografía utilizó poco el discurso poético como documento histórico. Numerosos críticos seguían pensando que el mensaje poético, orientado hacia la subjetividad y el afecto desde el romanticismo, no permitía el análisis sociológico. No obstante, como género y expresión literaria la poesía no podía ser atemporal. En palabras de Roland Barthes, «je doute qu'il y ait une essence de la poésie en dehors de son Histoire» ${ }^{17}$.

El carácter social e histórico de la escritura no puede pasar desapercibido; con mayor motivo cuando se habla de poesía de finales del Setecientos, género en el que se reflejan las preocupaciones e inquietudes sociales de los poetas por sus contemporáneos. La poesía fue un objeto de mucho consumo en el siglo XVIII, cargada de gran sociabilidad tanto en las tertulias como en la prensa. Los poemas de circunstancia eran muy frecuentes y ocuparon un lugar importante en la vida cultural y social de la época. Era habitual para las letradas y sus coetáneos comunicarse con sus allegados en versos ${ }^{18}$. Además, los textos

14 Comparé algunos años representativos de la sobre mortalidad de este siglo: el año 1733 tuvo un índice de mortalidad de 149, el año 1738, un índice de 150 (por cosecha catastrófica) y, en 1779, por culpa del accidente del puente San Alejandro, el índice llegó a 142. IGLESIAS RODRíGUEZ, Juan José: Una ciudad mercantil en el siglo XVIII: El Puerto de Santa María, Sevilla, 1991, p. 114, cuadro 15. Sólo son algunos de los ejemplos sacados del estudio de Juan José Iglesias.

15 El padre Antón hizo referencia a las colecciones de papeles curiosos de la región, citando «dos engendros poéticos de los muchos que inspiró la obra de O’Reilly, por haberlo él plantado de naranjos, demoliendo la capilla de las galeras, inservible, y ruinosa en 1780, y a una catástrofe espantosa, el hundimiento del puente de San Alejandro (...) causando aproximadamente cuatrocientas víctimas.» SANCHO DE Sopranis, H.: Historia del Puerto de Santa María, Cádiz, 1943, pp. 257-263. Citado por ANTón Solé, Pablo: Cádiz en la Carrera de las Indias, Aula Militar de Cultura, Cádiz, 1967, p. 9.

16 Martínez Alfonso, Manuel: El Puerto de Santa María en la literatura española. Ensayo de una geografía literaria, Madrid, 1962.567 pp.

17 BARTHES, Roland: Mythologie, París, 1957, p. 158. Citado por MARTI, Marc: «La poésie peut-elle être un document historique? Le cas de la poésie lyrique néoclassique espagnole» en Tiempos Modernos, 3 (2001) pp. 1-3.

18 Antes y después de ingresar en clausura M.G.H. se carteó en verso con su amiga Gerarda en numerosas ocasiones. Publicó en Madrid, Salamanca, Cartagena y Barcelona (siendo religiosa profesa) poesías dirigidas a «las de su sexo», pensando en un público femenino en la década de los noventa; eran poesías anónimas o firmadas con sus iniciales de seglar: H.D.S (Hija del Sol) y D.M.G.H. (Doña María Gertrudis Hore). V. MorAND, Frédérique: Una poetisa en busca de libertad, María Gertrudis hora y Ley (1742-1801). Miscelánea y Taraceas: versos, prosas y traducciones, Cádiz, Diputación, 2006 
circulaban, no era imprescindible publicar para alcanzar un importante público entre los letrados.

Por tanto, para conocer el grado de implicación social de las monjas de Santa María de Cádiz, me detuve en una de las creaciones de Sor Gertrudis y en particular en este romance endecasílabo manuscrito en relación con la catástrofe. Frente al desastre la novicia aprovechó un género poético de moda, premiado por la Real Academia este mismo año $1779,{ }^{19}$ para expresar su dolor y su compasión ante la tragedia. A mi juicio, no desconocía el poema premiado.

Lo que de verdad es social en la literatura, decía el sociólogo Lukács (Histoire et conscience de classe, 1923), es la forma. De nuevo en palabras de Roland Barthes, «la escritura (...) es el lenguaje literario transformado por su destino social, la forma captada en su intención humana y unida así a las grandes crisis de la Historia»; y si la escritura nace de la «reflexión del escritor sobre la función social de su forma ${ }^{20}$, se podría considerar el género elegido por la poetisa (premiado ese mismo año) como un conjunto de formas funcionando dentro de un mismo sistema de «comunicación social». ${ }^{21} \mathrm{La}$ escritura, aunque fuese poética, era un sistema de códigos en el que la autora ejerció su voluntad de difundir un «mensaje literario», apoyándose en una base cultural pero también, en este caso, profundamente histórica.

Descubramos el romance e intentemos analizarlo en su conjunto. A modo de introducción, Sor Gertrudis acusa la somnolencia en la cual el ser humano se ha adormecido y le avisa frente al castigo divino (cuartetos 1, 2, 3). Luego, el «yo» poético se entrega totalmente a Dios invocando su clemencia (cuartetos 4, 5). Tras el detenido estudio de su lírica, descubrí una evidente intertextualidad restringida o interna (relaciones intertextuales entre textos del mismo autor) en correlación con su experiencia de «mujer libre» y su reclusión conventual:

Mortales, que dormidos en el Lago/ de engañosos dorados pasatiempos,/ ni los más manifiestos desengaños/ consiguen del Letargo algún Recuerdo./Mirad en los avisos repetidos/ la amenaza fatal a vuestros yerros,/ y prepare la enmienda en tanto estrago/ el aspecto feroz del escarmiento./22

La elección del vocabulario (engañosos dorados pasatiempos, desengaños, avisos repetidos, amenaza fatal, escarmiento), tan cerca de otras de sus composiciones, evidencia la relación semántica reiterativa y circular propia de la lírica de esta extraña monja casada ${ }^{23}$. Podríamos analizar las figuras de estilo del

19 Prieto, Antonio: «Del camino y temperamento de la poesía dieciochesca» en Coherencia y relevancia textual: De Berceo a Baroja (Madrid) (1980) pp. 187-190.

20 Citado por MARCheSe, Ángelo y ForRADELLAS, Joaquín: Diccionario de retórica, crítica y terminología literaria, Barcelona, 1994, 4. ${ }^{\text {a }}$ ed., pp. 138-140.

21 ZIMA, Pierre: Manuel de sociocritique, París, 1985, p. 45.

22 B.N.M.: Hore María Gertrudis, Ms 4061, fols. 272-273. V. Apéndice 1.

23 Me parece importante subrayar que fue la única de las cuatro escritoras de la segunda mitad del XVIII español reconocidas hoy en día por la crítica (las otras son Josefa Amar y Borbón, 
poema como lugares estratégicos en los que se expresaron los distintos niveles del discurso poético, así como sus relaciones complejas entre la catástrofe y su historia personal. Pero estemos atentos a las figuras de construcción, al orden de las palabras (metáfora, metonimia, alegoría...), a las figuras de pensamiento, es decir a las que conciernen al enunciado completo (apóstrofe, exclamación, hipótesis, ironía) como elemento pertinente para entender su creación, aunque no trataré el mensaje poético como un mero hecho lingüístico, sino como un acto de escritura en el que la relación entre el emisor y el destinatario vehicula un mensaje de una forma determinada.

En este caso, Sor Gertrudis invoca a Dios, el único en el que el Mortal puede depositar su confianza, un Dios de toda bondad; la poetisa recuerda la ofensa hecha al Todopoderoso donde la Esperanza, una virtud teologal que conocía bien $^{24}$, constituye el único recurso:

/De vuestra indignación contra nosotros/ i en qué parte Seguros estaremos !/ sólo a vos, ô Señor en tanta angustia/ la esperanza nos da Recurso Cierto./

Sólo a partir del séptimo cuarteto, evoca la catástrofe vivida por El Puerto expresando, primero, las consecuencias del accidente usando los llantos eternos, metonimia del sufrimiento engendrado por la catástrofe:

/Dígalo entre otros muchos espantosos/ sobre los más Recientes de estos tiempos,/el más imponderable duro golpe,/que ha de llorar eternamente el Puerto./

\begin{abstract}
Margarita Hickey y Rosa Gálvez), en tomar el velo de la religión; María Gertrudis fue también la más amenazada por el olvido, por la dificultad de atribución de sus textos y pocos fueron los que se preocuparon por su lírica. Sus versos no fueron tan torpes como algunos los calificaron; en ellos pienso haber descubierto un verdadero testimonio poético, las huellas literarias de un sufrimiento únicamente femenino. En efecto, si el adulterio fue un tema ampliamente tratado en las novelas decimonónicas no es costumbre tratar el tema en la historia literaria y menos aún comentando poesías escritas por mujeres en la España del Setecientos. V. Sullivan Constance, «"Dinos, dinos quién eres": The Poetic Identity of María Gertrudis Hore (1742-1801)», Pen and Peruke: Spanish Literature of the Eighteenth Century, Monroe Hafter (ed.), Michigan Romance Studies, XII, 1992, pp. 153-183. LEWIS Elisabeth, Women Writers in the Spanish Enlightenment. The Pursuit of Happiness, Hampshire, England and Burlington, Ashgate Publishers, 2004.

24 Novena al Santo Cristo de la Esperanza que se venera en el Convento de Santa María de la Ciudad de Cádiz compuesta por una Persona devota de esta Venerable Imagen, Cádiz, 1778. 48 pp. Según las informaciones dadas por Cambiaso: «Impresas corren varias composiciones, traducciones de salmos y del «Mater Dolorosa», una novena a la Esperanza, etc...». CAMBIASO, Nicolás María de: Memorias para la biografía y para la bibliografía de la isla de Cádiz, Imprenta de D. León Amarita, Madrid, 1830, Tomo II, p. 76. Unos detalles retomados por CUETO, Leopoldo Augusto: Poetas líricos del siglo XVIII (ed. orig.: 1869/1875), B.A.E, Tomo III, 67, Atlas, Madrid, 1953, p. 553. Adolfo Castro leyó y publicó el prólogo de esta Novena atribuyéndole la autoría. CASTRO, Adolfo «María Gertrudis Hore de Fleming, la Hija del Sol La R.M. de la Cruz y Hore -Mirta-», La moda elegante, núm. 32, el 30 de agosto de 1870, pp. 262-263 y núm. 33, el 6 de septiembre de 1870, pp. 269270. Para mí no hay la menor duda, la Novena fue escrita por ella. Además, un documento conventual (sin clasificar) atribuye la autoría de esta creación a la Madre Gertrudis Hore.
\end{abstract}


Verdadera religiosa en el sentimiento, Gertrudis se propone sufrir en memoria ese terrible accidente. Entonces, empieza una versificación apasionada y apasionante sobre una tragedia de la que no pudo ser testigo directo, pero un acontecimiento que alguien del exterior le contó. ¿Una carta? ¿Un testimonio oral? Sea lo que fuere el realismo, el ritmo y el entusiasmo exaltado con los que la religiosa contó este funesto evento no dejaba duda alguna sobre el talento creativo de la gaditana, tampoco sobre la apertura hacia el mundo de este convento de clausura en el que una sociedad religiosa y profana convivía día a día ${ }^{25}$.

/Llegó aquel instante apetecido, /del día fatal Catorce de Febrero,/ Domingo Carnaval, donde los gustos,/ buscan Correspondencia a los deseos./ A las once del día, en que impaciente/ el Confuso Concurso de aquel Pueblo,/ por Siglos numeraba los minutos,/ que tardaban lograrse sus proyectos./

«Llegó el día fatal...» ${ }^{26}$ expresión habitual para hablar de la muerte a la que, de forma irónica y contrastada, la Hija del Sol añade ese «aquel instante apetecido", siniestro paralelismo que la poetisa asocia al espíritu de fiesta de este trágico domingo de Carnaval. La aparente precisión histórica con la que Sor Gertrudis cuenta este episodio me dejó algo escéptica: el 14 de febrero, a las once de la mañana... ¿Esto había realmente ocurrido aquel día? ¿A esa hora? Averigüé su discurso poético y descubrí, efectivamente, una vez acabada la obra y conducidas las pruebas bajo la dirección de O' Reilly que, el 14 de febrero, a las once del día, el puente San Alejandro había sido inaugurado ${ }^{27}$. Las precisiones de M.G. de la CH. (como le gustaba firmar), una religiosa apartada del mundo, eran exactas.

/Soberbio Puente que pretendió osado/ dominar las corrientes, poner freno,/ a las rápidas olas de océano/ cual si fuesen de Arroyo manso y quieto./

25 En este monasterio no vivían sólo Esposas de Dios sino también mujeres cuyo estatuto no era el de religiosa: había sirvientas, criadas, lavanderas, viudas que alquilaban una celda, mujeres nobles o de la alta sociedad en trámite con la justicia, o recluidas por malos tratos, niñas cuyos padres se habían ido de viaje sin saber donde dejarlas, o simplemente niñas huérfanas o educandas y, no podemos olvidar, a veces, en la clausura, también había esclavas. Localicé la partida de bautismo de María Manuela Josefa de la Encarnación, negra natural de Calavarí (Costa de Guinea) de trece años: fue esclava de la priora Manuela Fernández en 1774. Sin embargo, el clero prefirió atribuirla a una simple religiosa, encubriendo su presencia al servicio de la priora. A.P.S.C.: Libro de Bautismo (1773/1774), lib. 72, fols. 154-155. La presencia de esclavas en clausura fue un punto estudiado en varios artículos publicados en el I Congreso Internacional del monacato femenino en España, Portugal y América (1492-1992), Tomo I, Universidad de León, 1993.

26 Encontré esta expresión en una oración fúnebre: CAYO GRANDE, Joseph: Oración fúnebre que en las exequias que celebró por el Excmo. Sr. Duque de Monte-Llano, el venerable clero de la ciudad de Sanlúcar de Barremeda, El Puerto de Santa María, 1765, p. 31. Citado por PASCUA SÁnChez, M.a José: Actitudes ante la muerte en el Cádiz de la primera mitad del siglo XVIII, Cádiz, 1984, p. 66.

27 SÁNCHEZ GonZÁlez, R.: Op. cit., pp. 175-180. 
Si la fruición artística y verdadera es una operación semiótica dirigida a la apropiación de los códigos que subyacen en el texto, la intención de la autora cuando emitió este mensaje fue denunciar las acciones prepotentes de los humanos (Soberbio Puente, dominar) frente a la madre Naturaleza. Además, Sor Gertrudis no conocía únicamente el lugar y la fecha de la catástrofe sino que estába perfectamente enterada del origen del accidente: un error humano. Porque si no lo hubiese sabido, chubiese sentido la necesidad de precisar su propósito literario?

/No reflexivo indago los motivos/ no las Causas arguyo, nada inquiero,/ pues sólo lamentar tanto fracaso/ es el Sincero asunto de mi intento./

No se había olvidado de las costumbres de moda en el siglo ni tampoco de las diversiones en las que participó aludiendo a las /Comedias, Toros, y Banquetes/ cuando todavía era una seglar rica, hija y esposa de comerciantes irlandeses llegados a principios del siglo XVIII en Cádiz. Empleó términos técnicos, mencionó los materiales usados, y siguió versificando con el mayor ahínco sobre la catástrofe:

/Al grave peso faltan las Bisagras / que desquició el empuje de los Leños/sin poderlo estorbar las ligazones/ de las duras Cadenas ni los Pernos./De la máquina toda desunida/ cayeron dislocados los Maderos,/ siendo cada pedazo a competencia/ estrago más voraz y más Sangriento./

La sensibilidad ilustrada, a diferencia de la sensibilidad romántica, podía proyectarse sobre «un teorema matemático, un descubrimiento químico, un cuadro de excelente composición, una escena de maternidad gozosa», en palabras de Aguilar Piñal ${ }^{28}$. Entre innovación y originalidad, al tanto de las corrientes literarias de su tiempo, en estos dos cuartetos Sor María de la Cruz Hore, como en el poema de Moratín padre (La Diana o Arte de la caza de 1765), utiliza innovaciones terminológicas propios de la centuria ${ }^{29}$. Animó su narración introduciendo un toque de «autenticidad» a su versificación, como si de verdad hubiese sido testigo de aquella escena de pánico:

/En un minuto sólo pude verse/ (los pocos que mirar libres pudieron)/ i cuán falible, y errado es el dictamen/ del humano discurso, y sus proyectos !/ Los mismos Concurrentes que juzgaron/ hallarse de delicias Satisfechos,/ en el instante propio destrozados/ de la Parca terrible se advirtieron./Aquellos que en el lance se libraban/ del impulso mortal de algún fragmento/ en las ondas quedaron Sofocados/ sin poderlos valer ni aun el lamento./

28 Aguilar Piñal, F.: Historia literaria de España en el siglo XVIII, Madrid, 1996, p. 27. Maravall, J. A: La estimación de la sensibilidad en la cultura de la Ilustración, Madrid, 1979, p. 36.

29 Aguilar Piñal, F.: Op. cit., pp. 67-68. 
La función pictórica del segundo verso, entre paréntesis, acentuaba la angustia transmitida por la situación catastrófica. ¿Cómo pudo ser tan precisa? Y si la clausura no fuera más que un refugio del que no se escapa nadie, pero en el que la información autorizaba la evasión; recinto sagrado en el que las relaciones con el exterior permitían, y siguen permitiendo, a las monjas no estar tan apartadas del mundo de los seglares.

La alegría poética, la euforia en un primer momento (opuesta a la disforia), con la que la Hija del Sol contó el evento estaba representado en un acto capitular. Oficialmente, se recogió la presencia de una gran multitud oriunda de todas las clases sociales:

(...) manifestándose el júbilo, satisfacción y regocijo de las Gentes en la concurrencia de la mayor parte de todas clases eclesiásticas, seculares, y militares, y en las aclamaciones, y demostraciones festivas con que se manifestara el gozo y gusto universal de $\operatorname{todos}^{30}$.

Los primeros en pasar el puente fueron O'Reilly y su familia. Luego, la multitud estacionó en las compuertas y, por el peso, se rompieron. La municipalidad contabilizó 115 muertos pero la cifra exacta no se estableció nunca; hubo más de 100 víctimas sin lugar a dudas. Juan Cárdenas dijo que fueron 413 las víctimas. Juan José Iglesias habló de la muerte de 104 personas ahogadas (46 hombres y 58 mujeres) ${ }^{31}$.

/De las listas sacadas a esta Fecha/ se registra llegar a grande excelso,/ los Cadáveres tanto conocidos/ como otros que quien son aún no sabemos/ De oficiales, de Jueces, Sacerdotes,/ Religiosos, de Nobles, y Plebeyos,/Damas de todas Clases, y de Niños/ estas listas Componen sus Contextos./32

La piedra conmemorativa recogió 111 muertos. El 14, 15 y 16 de febrero tuvieron lugar los funerales de 105 personas en la iglesia prioral de la ciudad, de los que dos eran clérigos ${ }^{33}$. Fijémonos. Sor Gertrudis escribió el poema al día siguiente, después de las exequias, el día 17. Y como ella lo precisó, /De las listas sacadas a esta Fechal, después de que se estableciera oficialmente la lista de las víctimas. No podía dudar de la rapidez con la que María Gertrudis componía sus creaciones cuya calidad, a veces, se resentía ${ }^{34}$. No obstante, la escritura

30 A.H.M.P.M.: Actas capitulares, tomo 92. 1779. Cabildo 15 de febrero, fol. 77. Citado por SÁNCHEZ GONZÁLEZ, R.: Op. cit., p. 175.

31 CÁrdenas, Juan: Reseña histórica y descriptiva de la M.N. y M.L. Ciudad y G. Puerto de Santa María, El Puerto de Santa María, 1903, p. 116.

32 B.N.M.: Hore, María Gertrudis: Ms 4061, fol. 273.

33 Iglesias RodríGueZ, Juan José: Op. cit., p. 125.

34 Pienso en los dos poemas escritos en honor de Carlos IV adjuntado a su carta de 11 de marzo de 1796 dirigida a un amigo madrileño y publicada algunos días más tarde en el Diario de Madrid con sus iniciales H.D.S. V. Nota de pie núm. 1. 
tuvo un carácter fuertemente emocional para ella. Eligió empuñar la pluma ante este conmovedor acontecimiento, ante éste o bien ante cualquier otro con el que se sentía, ora de forma colectiva ora individual, implicada o comprometida $^{35}$.

Por tanto, su relato poético ino era el fiel reflejo de lo que ocurrió en El Puerto de Santa María este trágico domingo 14 de febrero? Desde la clausura la erudita monja compuso un romance endecasílabo en consonancia claramente historicista y supo mezclar el sentimiento, la compasión, la sensibilidad y el dolor con el más exacto rigor.

/La Madre ve expirar sus Caras hijas/ el Consorte a su Esposa ve muriendo/ y no pudiendo darles el Socorro/ todos quieren morir para no verlos./ En los brazos del Padre el tierno Infante/ extraído de las olas Casi Yerto,/ ensangrentado, herido, y palpitante/ despide su vital postrer aliento./36

Leemos una observación oficial sobre la catástrofe: «(...) un dato curioso, entre los fallecidos había un porcentaje superior de mujeres y también muchas personas de la misma familia» ${ }^{37}$. Una observación de la que podemos apreciar el fiel reflejo poético en el poema compuesto por Sor Gertrudis, novicia en el monasterio de Santa María. Aquella monja destacó por su capacidad para reproducir en versos un evento en el que, por cierto, no participó. Después de tan minuciosas precisiones históricas, M.G. de la CH. acabó religiosamente su narración invocando e implorando la bondad divina.

Tras indagar en este triste episodio, descubrí un apellido que no me era desconocido: Domingo Fleming. Fue uno de los testigos de la boda de la futura Madre Cruz con Esteban Fleming. Domingo Fleming fue nombrado tras la catástrofe para cuidarse de la conservación y del mantenimiento del puente, para que se cumplieran las ordenanzas y obligaciones ${ }^{38}$. ¿Acaso este hombre, tan bien informado de la catástrofe, vino a contarle lo sucedido en la clausura, tras las rejas del locutorio?

35 La serie de siete poemas sobre la difícil aceptación de la vida común en 1796. B.N.M.: HORE, María Gertrudis: Poesías Varias..., Ms 4061, fols. 274-277. Sus primeros poemas en honor a María Rosario Cepeda en 1768. V. MoRAND, Frédérique: Op. cit., pp. 203-208.

36 B.N.M.: HORE, María Gertrudis: Ms 4061, fol. 272.

37 A.H.M.P.M.: Actas capitulares, tomo 92. 1779. Cabildo 5 de marzo, fols. 122-129. A.H.P.I.M.P. (Archivo Histórico Parroquial de la Iglesia Mayor Prioral): Libro de Defunciones, lib. 11(1774/82), fols. 205-215 y Libro de Defunciones de la Hermandad de San Pedro, lib. 6 (1777/91), fols. 18 y 20. Citado por SÁNCHEZ GonZÁLEZ, R.: Op. cit., pp. 176-177.

38 Después del accidente la noticia fue transmitida al Consejo de Castilla y el puente cerrado hasta que se hicieran las obras. A.H.M.P.M.: Junta de Propios, leg. 3, 1779. Junta de 23 de abril, fol. 50. Ibídem: pp. 177-178 y p. 180. 


\section{2. ¿Cuál pudo ser la fuente de información de Sor Gertrudis?}

Yolanda Vega Moreno, mientras estábamos en la sala de manuscritos de la Biblioteca Nacional de Madrid, me enseñó una carta fechada a 16 de febrero de 1779, la víspera de la creación de Sor Gertrudis. Esa grafía no me era desconocida (aunque no sabría atribuirle nombre ni apellido) por haberla encontrado varias veces en el Archivo Diocesano de Cádiz. La carta en prosa, sin publicar, recogía los hechos ${ }^{39}$. Parecía difícil pensar que no fuera ésta la fuente de información original utilizada por la monja literata. A mi parecer, impulsó su creación, fue la tela de encuentros entre el mensaje poético y la tragedia. A menudo, las expresiones utilizadas por Sor Gertrudis se recogían en esta carta manuscrita; me parecía asistir «al momento privilegiado de la transcodificación» ${ }^{40}$, es decir, al modo de desvío innovador emprendido por la poetisamonja con relación al modelo. Tal vez, esta misma persona, quien copió los hechos relevantes de la tragedia, vino a contarle lo ocurrido. Cual fuese el conducto a través del que Sor Gertrudis conoció estos datos, gracias a esta carta podía proponer otras cifras y pormenores sobre la catástrofe. En ella se recogía, al menos el día 16, a más de 200 personas difuntas:

(...) Quedó dividido el concurso con la rotura del puente entre una y otra banda comenzaron los clamores al echar de menos cada uno los suyos recelando si perecerían o estarían de la otra parte, corrió la voz de la desgracia acudió lo restante del pueblo, iQué gritos! iQué llantos! iQué exclamaciones! Sólo viéndose pudo conocerse y más al verse q.e regresados todos los de la otra parte en Lanchas, y Botes iban reconociendo las faltas ${ }^{41}$.

Por otra parte, tenía detalles, a mi parecer, ignorados hasta la fecha sobre cómo se salvó la esposa del conde O’Reilly:

(...) y entre ellas hubiera sido la Genérala, a no haberla sujetado por la ropa el corrector de la victoria, y d. Bernardino de Bizarrón q.e estaban a sus espaldas, sobre el citado pilar cayendo todos los q.e estaban delante haciéndolo Corte ${ }^{42}$.

Esta carta ofrecía mayores explicaciones sobre el gran número de víctimas, cómo tuvo lugar el rescate y cómo se encontraron los cuerpos:

Como no se previó el daño los socorros no estuvieron prontos y los retardó más el pavor de todos, y del mismo Gen.l. (...) A las doce del día se comenzaron a

39 B.N.M.: Papeles Varios de carácter literario, histórico y religioso referentes a los siglos XVII y XVIII. S. XVIII (252 ff.) Procedente de la Biblioteca del Duque de Osuna, Ms 4039, fols. 236241.V. Apéndice 2. «Puerto de S.ta María, 16 de febrero de 1779».

40 MARCHeSE, Angelo y ForradelLas, Joaquín: Op. cit., p. 184.

41 Ibídem: fol. 239.

42 Ibid: fol. 238. 
sacar Cuerpos Cadavéricos, los q.e se iban poniendo en las casas inmediatas (...) Desde dha hora hasta esta mañana no se encontraban por las calles más q.e cadáveres en cunas, escaleras, y tablas; unos para las Iglesias, otros p.ra Hospitales y otros para sus respectivas casas; bien q.e algunas de éstas han quedado cerradas por haber perecido toda la familia. (...) Aun no han cesado de sacar cadáveres habiendo remanecido en la Playa de Cádiz Costa, y Portal de Jerez hallándose entre estos mismos q.e no se conocen y se cree ser forasteros ${ }^{43}$.

La aportación de documentos nuevos, tanto para el estudio de la catástrofe vivida por los vecinos del Puerto de Santa María, como para el mejor conocimiento del universo de la reclusión ya no permitía acatar el alejamiento de las religiosas gaditanas en sus respectivos conventos, tampoco alegar su completo retiro, ya que aquellas mujeres estaban al tanto de lo que ocurría en el exterior. Pude comprobarlo charlando con la abadesa o con la madre vicaria del convento de Santa María ${ }^{44}$; con la abadesa del monasterio de la Piedad en Cádiz o tomando café en el locutorio con la comunidad de clarisas de San Diego de Alcalá de Henares, así como hablando por teléfono con la Priora de las Carmelitas Descalzas de esta misma ciudad cervantina ${ }^{45}$.

\subsection{La venida de Carlos IV: entre privacidad y publicación periódica}

Otro escrito de María Gertrudis, una carta en prosa publicada en prensa, o sea un documento de origen intraconventual, me permitía enlazar el universo claustral con la sociedad civil e historiar la vida extraconventual en Cádiz desde otra perspectiva, es decir desde la clausura.

En medio de las ovaciones civiles y militares, el 2 de marzo de 1796, entre las once y las doce del mediodía, la familia real entraba en Cádiz. Fue un gran día para la ciudad que recibía, conmovida, la real visita. Un gran día no sólo para los habitantes de Cádiz sino también para las religiosas de Santa María y para María Gertrudis en particular: unos diez días después de la llegada de los Reyes, el 11 de marzo, la Hija del Sol escribió una carta a un amigo madrileño a

43 Ibid: fols. 239-241.

44 Me gustaría hacer constar que en este convento, el más antiguo de Cádiz, llegaron a ser tres religiosas (la Reverenda Madre y otras dos), expuestas al cierre de su institución por decisión ajena. Ahora son siete: Sor María Luz, sustituyendo a Sor Asunción ahora vicaria, es la actual priora, Sor Ana María la cocinera, Sor Mónica, Sor Carmen María, Sor María Ángeles y Sor Lory.

45 Miguel de Cervantes tuvo tres hermanas: Andrea (nacida en 1543), Luisa (1546) y Magdalena (nacida en 1554 en Valladolid). Luisa profesó con el nombre de Sor Luisa de Belén; ingresó a los 19 años y era ya novicia cuando conoció a Santa Teresa de Jesús por sus repetidas estancias en el convento de Carmelitas Descalzas «La Imagen», monasterio fundado el 11 septiembre de 1562 por la venerable María de Jesús. Luís ARMiÑán, Las Hermanas de Cervantes, José Porter, Barcelona, 1957, pp. 121-137. 
fin de contarle el evento ${ }^{46}$. Fue publicada en la prensa el día 29 de marzo y ofrecía, entre otros, un testimonio de la emoción causada entre las monjas por la visita de Carlos $\mathrm{IV}^{47}$. La misiva no permitía pensar que éstas vivían apartadas del siglo sino que, asimismo, se interesaban por estar al corriente de las idas y venidas de Sus Majestades. De esta manera daba comienzo la carta:

Ya es tiempo, amigo mío, de que yo tome la pluma para dar a Vuestra Merced parte de la que me ha tocado en el común alboroto por la venida de los reyes nuestros Señores a esta Ciudad; pero esto quiere tomarse despacio ${ }^{48}$.

El principio de la carta revelaba, una vez más, el gusto y la importancia del acto de escritura para la poetisa quien, ante una situación que le interesaba, le conmovía, no podía retener el correr de la pluma.

Primeramente nuestros mozos de Comunidad con algunos días de anticipación acopiaron en su estrafalario cuarto, ensaladas, berzas, y todos aquellos comestibles, que sin mayor riesgo de podrirse se pueden guardar, para de este modo tener más libres sus pies, y su tiempo a costa de nuestro pobre estómago y paladar ${ }^{49}$;

En algunas líneas, entendemos el por qué de estos hombres del exterior, los mozos de torno, frente a las necesidades de abastecimiento de una congregación bastante numerosa ${ }^{50}$. Los preparativos para recibir al rey y a su familia no generaron aumento de comestibles, tampoco de sueldos. Por tanto, la ración alimenticia de las monjas corría peligro. De esta ayuda hubieran podido, quizás, encargarse los poderes eclesiásticos conociendo las dificultades económicas de las comunidades femeninas en el siglo XVIII y, en particular, las de la comunidad de Santa María.

Testigo privilegiado de su tiempo, Sor Gertrudis hizo penetrar al lector en la organización conventual, en el momento en que las religiosas, emocionadas, se consagraban en exclusiva a la preparación de dicha recepción: «mientras que en cada celda no se pensaba más que en coser y trazar los adornos de las muchachas, que con general licencia salían de la clausura». Siguiendo las indicaciones de Sor Gertrudis era fácil comprender que las niñas educadas en el con-

46 «La monja literata escribió a un amigo de Madrid.» Citado por CASTRO, A.: «María Gertrudis Hore de Fleming, la Hija del Sol La R.M. de la Cruz y Hore -Mirta» en La moda elegante, núm. 33, 6 de septiembre de 1870, p. 269.

47 B.N.M.: Hore, María Gertrudis, Diario de Madrid, núm. 89, Martes 29 de Marzo de 1796, pp. 365-367.

48 Ibídem, p. 365.

49 Ibid.

50 En 1796 eran 39 religiosas, añadiendo al menos una criada por cada religiosa, además de seglares residentes y niñas. En 1801, habían 82 mujeres en la clausura de las cuales 33 eran religiosas. A.D.C, Sección I. Secretaría. Despacho de los Obispos. Fray Martínez de la Plaza (1792), leg. 42, fol 54. A.M.C., Padrón. general (1801), Ms 1029, fol. 137. 
vento tuvieron, para esta ocasión, el acuerdo de toda la comunidad para salir fuera de la clausura y acoger al séquito real vestidas con sus más bonitos trajes. Me pregunté si esta medida había sido ejecutada simplemente para acoger, con toda cortesía, a Carlos IV, o bien si fue decidida para que se olvidara la existencia en clausura de aquellas niñas, a menudo turbulentas y, aparentemente, bastante numerosas en Santa María en aquella época. ${ }^{51}$ María Gertrudis reseñaba una indicación temporal de una semana para resolver todos los preparativos. Siete días durante los cuales la actividad conventual fue intensa. La confección de adornos y vestidos en la que participó con entusiasmo le obligó a encerrarse en su celda durante todo este tiempo:

Lo fue aquella tanto en mi celda, que uniéndome con otra Religiosa, me obligué a quedarme sola por ocho días, no obstante un catarro furioso con calentura todas las noches. En fin llegó el dichoso día, claro, pero friísimo, y mucho más en los miradores, donde nos mantuvimos desde las ocho de la mañana hasta cerca de las doce que llegaron sus Majestades, entretenidas en ver formar el cordón de la tropa, con ver pasar las llaves de la Ciudad, que el Granadero que las llevaba, levantó en alto para mostrárnoslas, y sobre todo con la esperanza de la Real vista ${ }^{52}$.

El ademán del granadero me enseñaba la plena integración de las monjas en la vida de los gaditanos: no las ignoró, ni se le ocurrió olvidarse de su presencia, tampoco de su participación, desempeñando un papel de interés a lo largo de este regio acontecimiento.

La posición geográfica de su monasterio, en la «Montaña de Santa María», según se denominaba el barrio a fines del siglo XV, era importante de recordar. La maqueta de caoba y marfil, realizada entre 1777 y 1779, conservada en el Museo Municipal, permitía contemplar la situación: el monasterio se encontraba a la entrada de la cuidad, pasando la Puerta de Tierra y haciendo frente a la Plaza de Toros, cerca de la Cárcel Real, pero sin que ningún edificio estorbase su ángulo de visión. La presencia de celosía de madera y rejas, como era habitual, en todos los arcos (cinco de frente y uno lateral) componían el mirador alto (hoy injustamente cerrado); permitía a la comunidad religiosa participar en actos como el referido, o simplemente dejar, por un momento, sus miradas de contemplativas perderse a lo lejos, en la inmensidad del océano.

${ }^{51}$ En efecto, debido a la cercana decisión de establecer la vida común (el decreto tenía fecha de 23 de abril de 1796), todas las mozas que no trabajaban en ese momento por el monasterio habían de salir de la clausura. La comunidad vivía desde su establecimiento (1527) bajo el régimen de vida privada o particular: es decir, comían cada una en su celda sin tener la obligación de ir al refectorio, tampoco de reunir sus ingresos a fin de redistribuir el dinero de forma más equilibrada. V. MORAND, Frédérique: "Acercamiento a la indumentaria y otras modas dieciochescas en boga en la clausura gaditana de Santa María del Arrabal»en Cuadernos del Estudio del Siglo XVIII (Oviedo) 4 (2004), pp. 157-178.

52 B.N.M.: Hore, María Gertrudis, Diario de Madrid, núm. 89, p. 366. 
Finalmente, llegó el gran día. Las monjas no estaban dispuestas a perderse algo de la entrada triunfal de su eminencia Carlos IV, tampoco la de sus seguidores. El séquito pasó la muralla y se fue en dirección a Santa María. Leemos un artículo publicado en el «Semanario erudito y curioso de Salamanca», el sábado 19 de marzo de 1796:

La carrera vistosamente colgada (tendida por toda la Tropa de la Guarnición) principiaba desde la Puerta de tierra, por donde entraron Sus Majestades tomando sobre la izquierda delante del Matadero, Cárcel Nueva, Plaza de toros, (...) Casa de las cuatro torres, hasta la del Marqués del Castillo de San Felipe, destinada para el Real alojamiento, en donde han permanecido Sus Majestades y demás Familia Real sin novedad en su importante salud ${ }^{53}$.

Las monjas estaban en primera fila para seguir el recorrido de Sus Majestades. Leemos ahora a Sor Gertrudis:

Por fin llegó ésta, pasando despacio los coches, en el primero el Rey, la Reina, y una Infanta, en el segundo y el tercero Personas Reales, pero no sé quienes; las conocí por el tiempo que estuvieron presentadas las armas, y en todo hasta unos nueve coches. El Gobernador iba delante del Rey a caballo: luego me quedó la diversioncilla de acá dentro: una decía que no era el Rey, porque no le rindieron las armas, otra que no iba sino en el último coche, otra que el primero sólo era de familia, etc. en vano me cansaba en decirlas que aquel honor era sólo para el Rey del Cielo: todas gritaban y yo me vine 54 .

Disponía de algunas informaciones sobre la estancia real, principalmente por la prensa. Ahora, en palabras de Sor María de la Cruz, tenía más detalles sobre la composición de aquella escolta así como la posibilidad de reconstruir, en parte, el evento desde otro ángulo.

María Gertrudis dejó constancia de la atmósfera conventual, describió las torpes emociones de algunas, reveló que el rey había visitado el mirador alto para poder admirar la reciente obra del arquitecto Ler, las murallas y las fortificaciones; contó que podía oír los vivas desde su celda y, con el tono de la exaltación, la que firmó esta carta como H.D.S., relató con fuerza su arrebato:

(...) Al oír esto dejo la ventana, me precipito por la escalera, llego a la celda, me toco, tomo el manto, salgo al claustro, la Madre Abadesa me encuentra y dice: al instante unos versos para presentar nuestra ofrenda (de primorosas flores) a los reyes, formo ocho renglones largos en hilera de octava: llego al coro sin aliento, y (déjeme Vuestra Merced respirar) ya pasó el Rey de largo, y fue hacia Capuchinos, donde fue igual la agitación, más prevenciones, y el mismo logro que nosotras.

53 Semanario erudito y curioso de Salamanca, núm. 313, Sábado 19 de Marzo de 1796, pp. 271-272.

54 B.N.M.: Hore, María Gertrudis, Diario de Madrid, núm. 89, p. 367. 
Notemos el «déjeme respirar» que puso entre paréntesis en su narración entusiasmada, la rapidez y el ritmo de su lírica exaltada, volviendo a vivir, con su único lector, en un principio, aquel momento de emoción intensa para todas. La Hija del Sol describió con más premura el segundo y el tercer día al armonizar la llegada real con el ritmo de sus rezos. En pocas palabras, demostraba su capacidad de descripción y síntesis:

No obstante, por si acaso venía al Jubileo, se deja el coro para la noche: el segundo día lo mismo: ya va por la mar, ya viene por la tierra, y nosotras al mirador, al campanario, al cochecillo (que es un caramanchón sobre el campanario) y aguardando la oración al Jubileo, y Maitines de noche. El tercer día que el Rey viene, que la Reina se va, que a ver el combate de las navas, a la noche a la iluminación, a la tarde a los toros, a oír tonterías; que aquel es el Rey, que no es sino el otro, que la Reina, que las Infantas, si son, si no son, y a oír contar muchísimas patrañas 5 :

Ya llegó el último día, en palabras de la poetisa. Era sábado. Eran las siete de la mañana. Las monjas estaban a la espera, apostadas en el mirador, al acecho, testigo privilegiado en el ámbito urbano.

Su lírica ilustraba la participación activa de las religiosas de Santa María en la ciudad durante la segunda mitad del siglo XVIII. Sor Gertrudis tuvo conocimiento, como cualquier otra gaditana, de todas las actividades reales, tanto en Cádiz como en sus alrededores. Por tanto, no estuvieron tan apartadas del universo social gaditano. Con mayor motivo, conociendo las incesantes idas y venidas de seglares (tanto hombres como mujeres) en la clausura de Santa María a lo largo de la centuria. Un hecho que resultó algo perturbador para las religiosas pero, a la vez, impidió el aislamiento total con sus coetáneos en el siglo ${ }^{56}$. En palabras de Sor Catalina Gordillo, religiosa en este convento de contemplativas Calzadas:

Quisiera que su Santa Ilustrísima mandara que seglares, y doncellas, se vistieran, todas de uniforme por que no parece esto convento, sino que es un Rincón del siglo, pues no carecemos de estar viendo todas cuantas modas se estilan, si-

55 Ibídem. Por la tarde la familia real visitó las fortificaciones y el castillo de Santa Catalina. El día 3, por la mañana, en un barco cerrado de cristal se fue al arsenal de Carraca y subió a bordo del barco Trinidad, mientras otros barcos le acompañaban. Carlos IV volvió a las dos para almorzar y a las cuatro asistió a una corrida de toros en compañía de la reina. El 4 de marzo, de nuevo se fue al arsenal de Carraca y luego, almuerzó; por la tarde, el rey salió en compañía de la reina por las calles de Cádiz. La ciudad había previsto un concierto en el teatro pero no asistieron: el concierto y el baile duraron hasta las doce. El 5 de marzo, por la mañana, a las siete y cuarto, la pareja real salió para Jerez de la Frontera. Ravina, M.: Don Nicolás de la Cruz y Babamonde, Conde de Maule. De Cádiz y su comercio, Tomo XIII del viaje de España, Francia e Italia, Universidad de Cádiz, 1997, p. 151.

56 V. MORAND, Frédérique: «El papel de las monjas en la sociedad española del setecientos» en Cuadernos de Historia Moderna (Madrid) 29 (2004), pp. 45-64. 
guiéndose aquí igualmente el lujo entre unas y otras, por que todas van a las que más pueden sobre salir. ${ }^{57}$

Para formar la hipótesis del aislamiento conventual el profesor Morgado se apoyó sobre la poca devoción de los fieles hacia aquellas comunidades. Efectivamente, entre 1700, 1725 y 1759 sólo el 1,07\% de las misas pedidas por los testadores (esencialmente mujeres) fueron celebradas en el convento de Candelaria, el $1,11 \%$ en el de Santa María y el 0,64\% en el convento de las Descal$\mathrm{zas}^{58}$. Las misas pedidas por los testadores, aunque de interés para el estudio, no me parecían elementos suficientes para deducir el retraimiento de aquellas mujeres. Muchos otros factores tendrían que ser estudiados para descubrir los vínculos del monjío con la sociedad civil: aquel romance endecasílabo compuesto el 17 de febrero de 1779 sobre la tragedia vivida por la ciudad del Puerto de Santa María, su carta a un amigo sobre la venida de los Reyes, o la localización de otra carta escrita por uno de sus criados todavía a sus órdenes el 4 de enero de 1781, eran pruebas de ello:

(...) Cumple con sus órdenes: comise a D.a Ri(ta) 6 libras de lomo que son 24 r.s p.r que así me lo mando su merced (...) Dan todas m.s Gracias a Vm y han celebrado mucho el lomo y ahora celebran la pava muchos más pero d.a Rita siente como yo la omisión. (...) Yo no soy largo p.r no ser molesto (...) me remito a su obediencia cuya vida guarde Dios los años de su deseo $(\ldots)^{59}$

María de la Cruz Hore mantuvo contactos con «los de fuera» a lo largo de su monacato, mandando pedidos de tiendas a su fiel servidor para abastecer sus necesidades religiosas, creando relaciones sociales al recibir amigos y familiares detrás de las rejas del locutorio o, quizás, en la misma clausura. Sus testimonios, fuesen publicados, fuesen manuscritos, daban constancia de la presencia y de la influencia de esta comunidad en la sociedad gaditana a finales de la centuria.

La epidemia de fiebre amarilla era otro ejemplo de ello: M.G.H. publicó tres glosas en la imprenta de Manuel Carreño entre 1800 y 1801. Estas publicaciones revelaban su conocimiento de la epidemia, el comportamiento de los vecinos así como el de las autoridades ${ }^{60}$.

Testigos privilegiados de los avatares y de los momentos de alegría de los gaditanos, al corriente y partícipe de las modificaciones y acontecimientos so-

57 El documento no está firmado, tampoco tiene fecha, pero en la lista nominativa establecida en 1796 está atribuido a la monja Catalina Gordillo. A.D.C, Fray Martínez de la Plaza, leg. 42, fol. 52.

58 Morgado García, A.: Op. cit., p. 180. Pascua Sánchez, M.a José: Actitudes ante la muerte..., p. 274.

59 A.D.C.: Sección IV. Varios. Correspondencia particular del Magistral J. Martín Guzmán. Director administrador del hospital (1776-1780), leg. 3196, s.n. Publicada en MORAND, Frédérique: Doña María Gertrudis Hore (1742-1801), vivencia de una poetisa gaditana..., p. 269.

60 Glosas: «Aplaca, mi Dios, tu enojo», «Ave, adorada María,» cuya creación fue publicada bajo anónimato, y «Purísima Concepción». B.N.M.: HORE, María Gertrudis, Ms 4061, fols. 247-249. 
ciales de la ciudad, las monjas gaditanas no estuvieron tan encerradas en sus respectivos conventos. Al fin y alcabo tuvieron bastante relación con el núcleo urbano y no constituyeron, en absoluto, un mundo aparte.

Compartía la idea de Sonja Herpoel al afirmar que siempre las monjas intentaron guardar contacto con el exterior. No rechazaron su época, sino al contrario, formaron parte integrante de la sociedad en la que vivían, hospedadas en los santuarios de la frágil memoria colectiva en España durante la Época moderna ${ }^{61}$.

61 Herpoel, Sonja: «Un mar de misterios": la religiosa española ante la escritura» en Breve bistoria feminista de la literatura española (en lengua castellana), Desde la Edad Media hasta el siglo XVIII (Puerto Rico) (1997) p. 208. 
Apéndice 1.

\section{Habiendo sabido un Sujeto el desgraciado acaecimiento del Puerto de Santa María prorrumpió en el Siguiente.}

\section{Romance endecasílabo}

Mortales, que dormidos en el Lago de engañosos dorados pasatiempos, ni los más manifiestos desengaños consiguen del Letargo algún Recuerdo.

Mirad en los avisos repetidos la amenaza fatal a vuestros yerros, y prepare la enmienda en tanto estrago el aspecto feroz del escarmiento.

Y vuestra Majestad, Deidad Eterna absoluto Señor del Universo, que dispensáis distributivamente las penas merecidas, o los premios.

Ved, que sois infinito en lo piadoso, suspended el azote justiciero, mirando la malicia delincuente en tan débiles míseros objetos.

De vuestra indignación contra nosotros ien qué parte Seguros estaremos! sólo a vos, ô Señor en tanta angustia la esperanza nos da Recurso Cierto.

Infelices, miramos los Mortales la serie lamentable de Sucesos, como acaso del todo accidentales, y son de tu bondad justos decretos.

Dígalo entre otros muchos espantosos sobre los más Recientes de estos tiempos, el más imponderable duro golpe, que ha de llorar eternamente el Puerto.

Y para que lo justo de su pena mayor materia dé a su Sentimiento permítame el dolor, que en breves Rasgos presente a la memoria algún diseño.
Llegó aquel instante apetecido, del día fatal Catorce de Febrero, Domingo Carnaval, donde los gustos, buscan Correspondencia a los deseos.

A las once del día, en que impaciente el Confuso Concurso de aquel Pueblo, por Siglos numeraba los minutos, que tardaban lograrse sus proyectos.

Sagrada Ceremonia dio principio a bendecir Solemne en digno Celo, la brillante Capaz arquitectura del Construido Reciente Puente nuevo.

Soberbio Puente que pretendió osado Dominar las corrientes, poner freno, A las rápidas olas de océano cual si fuesen de Arroyo manso y quieto.

No reflexivo indago los motivos no las Causas arguyo, nada inquiero, pues sólo lamentar tanto fracaso es el Sincero asunto de mi intento.

La muchedumbre toda que atraída de la esparcida voz de los festejos, en las Comedias, Toros, y Banquetes, prevenidos al fausto del estreno.

Allí esperaba ser con los Patricios al paso cada cual de los primeros, para solicitar la primacía unidos a la empresa acometieron.

Mas i ay dolor! no bien las firmes plantas, toda la superficie del terreno ufanas ocuparon cuando todas al precipicio Corren del desempeño. 
Al grave peso faltan las Bisagras que desquició el empuje de los Leños sin poderlo estorbar las ligazones de las duras Cadenas ni los Pernos.

De la máquina toda desunida cayeron dislocados los Maderos, siendo cada pedazo a competencia estrago más voraz y más Sangriento.

No copioso granizo que impelido de opaca densa nube inunda el Suelo, se puede comparar el incesante diluvio racional de los dos sexos.

iEn un minuto sólo pudo verse (los pocos que mirar libres pudieron) cuán falible, y errado es el dictamen del humano discurso, y sus proyectos!

Los mismos Concurrentes que juzgaron hallarse de delicias Satisfechos, en el instante propio destrozados de la Parca terrible se advirtieron.

Aquellos que en el lance se libraban del impulso mortal de algún fragmento en las ondas quedaron Sofocados sin poderlos valer ni aun el lamento.

La Madre ve expirar sus Caras hijas el Consorte a su Esposa ve muriendo y no pudiendo darles el Socorro todos quieren morir para no verlos.

En los brazos del Padre el tierno Infante extraído de las olas Casi Yerto, ensangrentado, herido, y palpitante despide su vital postrer aliento.
Todo es confusión, todo pasmo, susto y suspiros de Agonizantes ecos, sin poder dar auxilio en tanta pena vínculos de Amistad, ni parentesco.

Al común alarido lastimoso, Conmovido de espanto todo el Pueblo vacilante discurre en dar alivio mas todos necesitan el Remedio.

Raro puede encontrarse que la angustia de tal Calamidad le dejó exento, pues en lo general de la Tragedia se incluyen infinitos para el duelo

De las listas sacadas a esta Fecha se registra llegar a grande excelso, los Cadáveres tanto conocidos como otros que quien son aún no sabemos

De oficiales, de Jueces, Sacerdotes, Religiosos, de Nobles, y Plebeyos, Damas de todas Clases, y de Niños estas listas Componen sus Contextos.

¡ Ô ! tremenda Deidad a cuyo arbitrio toda existencia pende si Usáis Recto de Vuestro Poder, para aniquilarnos como ha de subsistir el Universo.

Tened misericordia Juez piadoso nuestra débil miseria Conociendo y nosotros con lágrimas debidas su favor, y Piedades imploremos. ${ }^{62}$

Cádiz y Febrero 17 de 1779 -

62 B.N.M.: Hore, María Gertrudis, Poesías Varias (principalmente) del siglo XVIII, Tomo IV, Ms 4061 «Ex-Libris D. A-Mosty», fols. 272-273. De nuevo otro copista (el sexto en recopilar poemas de M.G.H.). 


\section{Apéndice 2.}

Puerto de S.ta María 16 de febrero de $1779^{63}$.

El actual estado en q.e se halla este pueblo parece deberlo manifestar, por sus efectos, como por ser el único objeto a el día.

Como el ídolo de este capitán g.l es proporcionar los objetos de la diversión a este Pueblo, y los de su contorno, habiendo a esto fin proporcionado un conjunto de espectáculos de placer, diversiones y alegría, en paseos, bailes, toros, y comedias en que ocupar el triduo del carnaval, estreno del nuevo puente con suma precipitación para el q.e hizo general convite, a los Prelados, Clero, y lo más distinguido del Pueblo al primer paseo de dho puente, citando para entre once, y doce de la mañana del Domingo 14 del corriente, con cuyo motivo, y haber corrido la voz de venir a bendecirlo el Obispo de Cádiz, serenidad del día, pasó a la otra banda concurrió todo el pueblo con multitud de forasteros movidos de la diversión de toros, y habiendo dispuesto dho S.or Exmô se pusiese un concierto de Música bajo de un víctor a su nombre, sobre el Pilar de la otra banda del río inmediato a los Portalones levadizos para el paso de las embarcaciones de el río de Jerez, y donde con motivo de la Música o dar principio a un baile, hizo parada al regresarse la Genérala y su comitiva sobre dhos Portalones, el tumulto de la gente, bien fuese por el excesivo peso de ella, o su falsa construcción se desplomaron dhos portalones cayendo al mar cuanto sobre ellos había desplomándose al mismo tiempo todo el artificio de hierros, cadenas, y maderos, q.e servían p.ra levantarlos al paso de las embarcaciones pereciendo (según consta hasta la presente) más de 200 personas y entre ellas hubiera sido la Genérala, a no haberla sujetado por la ropa el corrector de la victoria, y d. Bernardino de Bizarrón q.e estaban a sus espaldas, sobre el citado pilar cayendo todos los q.e estaban delante haciéndolo Corte.

En este momento trastorno la mano poderosa todo el placer en la escena más ${ }^{64}$ triste, y lamentable, q.e ha experimentado este pueblo viendo un espectáculo difícil a comparar, el conjunto de todas sus circunstancias, y resultas tan funestas en tan breve tiempo pareciendo imposible a prima facie tantas desgracias ni que hubiesen perecido tantas almas. Coadyuvó mucho a q.e pereciesen tantos estar la mar llena por la mucha agua q.e mandaba el canal del paso de los Barcos, y más q.e todo el derrumbo de dichos yerros, cadenas, y maderos q.e desplomándose sobre los q.e cayeron y arrojaron al caer les quitó la vida según se reconocen los cadáveres pues los más que se han sacado demuestran los golpes, no hinchándose como los demás ahogados siendo de estos los q.e cayeron debajo. Son m.s los heridos lastimados, y q.e no recibiendo golpe se comenzaron a ahogar a q.e morirán los más.

Como no se previó el daño los socorros no estuvieron prontos y los retardó más el pavor de todos, y del mismo Gen.l. Quedó dividido el concurso con la rotura del puente

63 Este manuscrito está dedicado al señor de Nava-Hermosa. Sin embargo, los siguientes folletos fueron añadidos más tarde. El manuscrito recopila principalmente eventos en el siglo XVII; curiosamente, ningún otro documento en este manuscrito hacía referencia a Cádiz. Agradezco a Yolanda Vega Moreno por indicarme esta referencia.

64 B.N.M.: Papeles Varios de carácter literario, histórico y religioso referentes a los siglos XVII y XVIII. S. XVIII (252 ff.) Procedente de la Biblioteca del Duque de Osuna, Ms 4039, fol. 238. 
entre una y otra banda comenzaron los clamores al echar de menos cada uno los suyos recelando si perecerían o estarían de la otra parte, corrió la voz de la desgracia acudió lo restante del pueblo, iQué gritos! iQué llantos! iQué exclamaciones! Sólo viéndose pudo conocerse y más al verse q.e regresados todos los de la otra parte en Lanchas, y Botes iban reconociendo las faltas.

iA las doce del día se comenzaron a sacar Cuerpos Cadavéricos, los q.e se iban poniendo en las casas inmediatas, andando todos sobresaltados en reconocim.to y solicitud de los suyos! Qué habría en estos pasos de hallar el marido a la mujer está a su marido, el Padre, la Madre a su hijos, estos a su Padres, pudiendo cada uno hacer la más prudente consideración de este lance.

Desde dha hora hasta esta mañana no se encontraban por las calles más q.e cadáveres en cunas, escaleras, y tablas; unos para las Iglesias, otros p.ra Hospitales y otros para sus respectivas casas; bien q.e algunas de estas han quedado cerradas por haber perecido toda la familia.

Para acreditar la multiplicidad ${ }^{65}$ y constitución, en q.e se halla este pueblo debe suponerse no haber doblado p.r ninguno ni haberse echo más entierros públicos q.e el del Alcalde mayor, Alguacil mayor, y otros dos o tres; que salieron tres cruces de la Parroquia sólo a conducir a la dicha, sin hacer oficios, y q.e no pudiendo dar abasto en todo el día de ayer, y noche se mandó llevasen los cuerpos, y se positasen ${ }^{66}$ en toda la Iglesia, y sus capillas, depositándose, y enterrándose igualmente en los Convent.s y Hospitales, disponiendo se abriesen Zanjas en los cementerios para los q.e no cupieron en Bóvedas, y sepulturas. De suerte que será difícil hallar muchas casas en q.e no haya sido comprendido, en esta desgracia alguno de la familia. En estos días no ha podido haber en Iglesia alguna manifestación de sacramento por no haber q.n concurriese a ellas mediante hallarse comprendidos en este quebranto, siendo de admirar, q.e en el castillo donde concurría tanta gente estas noches sólo se han contado en la q.e más doce personas, razón la más poderosa del general duelo en q.e se halla el Pueblo.

Aún no han cesado de sacar cadáveres habiendo remanecido en la Playa de Cádiz Costa, y Portal de Jerez hallándose entre estos mi.s q.e no se conocen y se cree ser forasteros. Entre todos los q.e han perecido son los más visibles del Pueblo los q.e expresa la adjunta nota, y en q.to de presente se puede decir.

D.n Juan Gerónimo Montijano Alcalde Mayor de esta ciudad

D.n Juan Bapt.a Navarro Alg.l m.or

D.n Juan Izquierdo cura de esta Prioral

D.n Alonso Tarriba Presbítero

Fr. Juan Mogro Mínimo

D.n Rafael Lisa

D.n Nicolás Lavarre

D.n Gregorio Molina Regidor y su hijo ${ }^{67}$

D.n Domingo Barreda el común

D.n Nicolás de Cañas mug.r e hija mayor

65 Ibídem, fol. 239.

66 No aparece el verbo «positar» en el diccionario de la Real Academia pero sí «posito» y «positura».

67 Ibid, fol. 240. 
TESTIGOS PRIVILEGIADOS EN EL ÁMBITO URBANO: LAS MONJAS DEL CONVENTO DE SANTA MARÍA... 1043

D.n Antonio Orlando del común

D.n Mig.l Chaves Médico

La Mujer de D.n Felipe Tili

D.n Antonio Abad Jernoso

D.n Manuel Romero de Sevilla

D.n N. Bargas, Clérigo menores de Jerez

D.n N. Medina de S.n Lucar

Además de los dichos constan más de 200 personas de todas clases ${ }^{68}$.

68 Ibid, fol. 241.

Hispania, 2006, vol. LXVI, no. 224, septiembre-diciembre, 1019-1044, ISSN: 0018-2141 